\title{
Prevalence of pre-gestational diabetes among the antenatal women attending a tertiary care center
}

\section{Renji S. R., Sujatha Thankappan Lekshmi*, Nirmala Chellamma}

\begin{abstract}
Department of Obstetrics and Gynecology, Sree Avittom Thirunal Hospital, Government Medical College, Trivandrum, Kerala, India
\end{abstract}

Received: 07 January 2017

Accepted: 27 January 2017

\author{
*Correspondence: \\ Dr. Sujatha Thankappan Lekshmi, \\ E-mail: kuttugayathri@gmail.com
}

Copyright: (C) the author(s), publisher and licensee Medip Academy. This is an open-access article distributed under the terms of the Creative Commons Attribution Non-Commercial License, which permits unrestricted non-commercial use, distribution, and reproduction in any medium, provided the original work is properly cited.

\begin{abstract}
Background: Number of pregnant women with preexisting diabetes is increasing. Hence the detection and management of diabetes from the beginning of pregnancy itself will help to improve the fetal and maternal outcome. Aim of the study was to determine the prevalence of pre-gestational diabetes among the antenatal women attending a tertiary care center and to study the associated factors.

Methods: This was a cross sectional study conducted in SAT hospital, Government Medical College, Trivandrum, Kerala, India for one year. HbA1C was the test used to diagnose diabetes. 400 women attending the OP in their first trimester were selected after informed consent. Socio demographic factors assessed by a structured questionnaire. Blood samples were taken for HbA1C. Diagnosis of diabetes was made at levels of $\mathrm{HbA} 1 \mathrm{C} \geq 6.5 \%$. Statistical tests used were mean, standard deviation, chi-square and odds ratio.

Results: Prevalence of pre-gestational diabetes was 3.8\%.in our study. Main associations were age more than 25 years, body mass index, family history of diabetes, history of intra uterine death, gestational diabetes in previous pregnancy, candidiasis and thyroid disease.

Conclusions: Screening of all pregnant women in first trimester itself for diabetes will help in early detection of pregestational diabetes, so that anticipation of adverse outcomes and proper management can be done in such cases.
\end{abstract}

Keywords: Gestational diabetes, HbA1C, Pre-gestational diabetes

\section{INTRODUCTION}

Diabetes in pregnant woman may be pre-gestational or gestational. The prevalence of pre gestational diabetes among woman in their early reproductive years is increasing. The overall prevalence of pregnant woman with pre-gestational diabetes doubled from 1999 to 2005 . On the other hand prevalence of GDM remains constant at about 7.5 to $10 \%$ during the same interval. Identification of women with pre-gestational diabetes is critical to minimize the risk to the mother and fetus.

Over the past three decades, the number of people with diabetes mellitus has more than doubled globally, making it one of the most important public health challenges to all nations. Type 2 diabetes mellitus (T2DM) and prediabetes are increasingly observed among children, adolescents and younger adults. ${ }^{1}$

Yang and associates found that diabetics experienced significantly worse pregnancy outcomes. Those women whose initial HbA1C concentrations more than $12 \%$ or persistent pre prandial glucose concentrations more than $120 \mathrm{mg} / \mathrm{dl}$ were at increased risk. The incidence of major congenital malformations in women with type 1 diabetes is approximately $5 \%$.

World Health Organization in 2011 as well as American Diabetic Association (ADA) has accepted HbAlc as a diagnostic tool for diagnosing diabetes mellitus. Pre 
gestational diabetes was associated with approximately $50 \%$ of the birth defects. According to Johan et al glycated $\mathrm{Hb}$ is formed by non-enzymatic attachment of glucose to the end- terminal valine of the $\mathrm{Hb}$ beta chain and reflect average glucose concentration over the previous $8-12$ weeks. HbA1 $\mathrm{c}$ is increasingly being used for the diagnosis of diabetes $(48 \mathrm{mmol} / \mathrm{mol}$ corresponding to $6.5 \%$ ) or prediabetes $(39-47 \mathrm{mmol} / \mathrm{mol}$ $5.7-6.7 \%$ ) in non-pregnant women. A base line HbA1c value may predict the risk of adverse pregnancy outcome.

Diabetes prevalence is on the increase due to early onset of adulthood diseases among Asian Indian women. Cases of pre-gestational diabetes may be regarded as gestational diabetes in women in whom antenatal screening is done only in the second and third trimester of pregnancy. Early counselling and treatment in women with pre-gestational diabetes can improve fetal and maternal outcome. Studies of gestational diabetes were plenty whereas studies are less regarding pre-gestational diabetes.

\section{METHODS}

This is a cross sectional study conducted in Obstetrics and Gynecology, OP in the Department of Obstetrics and Gynecology, SAT Hospital, Government Medical College, Trivandrum, Kerala, India in a tertiary care center. The study duration was 1 year. Sample Size (n) is calculated using the formula $\mathrm{n}=4 \mathrm{pq} / \mathrm{La}^{2}, \mathrm{p}=$ prevalence of pre-gestational diabetes, $q=1-p, L=$ permissible error in estimation of $\mathrm{p}$ (usually fixed at $10 \%$ of $\mathrm{p}$ ), substituting the values we get $n=4 \times 0.5 \times 0.5 / 0.0025=400$.

Women in their first trimester of pregnancy were included in the study.

Women in their second and third trimester and cases of GDM were excluded from the study.

400 women attending the obstetric OP in their first trimester of pregnancy in SAT hospital were selected after informed consent. Socio demographic factors and history taken by a structured questionnaire. Blood sample taken for checking HbA1C. HbA1C level more than $6.5 \%$ was taken as the diagnostic criteria for diabetes.

\section{RESULTS}

The mean age of the study population was 27 years. The mean BMI of the study population was $24 \mathrm{~kg} / \mathrm{m}^{2}$. The mean $\mathrm{HbA1C}$ was 4.9. 20.3\% of patients in this study had BMI more than $25.65 .5 \%$ of patients belonged to rural area. $69.8 \%$ patients were unemployed, $65.3 \%$ had higher secondary education. $94.2 \%$ were belonged to low socio economic status group. $47.3 \%$ had family history of diabetes. $87 \%$ did not have the habit of exercise. $72.7 \%$ were having sedentary lifestyle. $25.3 \%$ had family history of hypertension. $32.8 \%$ were primi gravida and $35.3 \%$ were second gravida. $48.3 \%$ had one live child, $8.5 \%$ had history of IUD and $1.3 \%$ had history of neonatal death. $29.5 \%$ had history of abortions. $25.5 \%$ had history of GDM in previous pregnancy. $41.3 \%$ had history of urinary tract infection. $46.3 \%$ had history of thyroid disease. Prevalence of overt diabetes in the study group is $3.8 \%$.

Among the 15 overt diabetic patients (86.7\%) were having type II diabetes mellitus. $13.3 \%$ had type I diabetes mellitus (Table 1).

Table 1: Distribution of pre-gestational diabetes in the study group.

\begin{tabular}{|l|l|l|}
\hline $\begin{array}{l}\text { Presentational } \\
\text { diabetes }\end{array}$ & Frequency & Present \\
\hline Present & 15 & 3.8 \\
\hline Absent & 385 & 96.2 \\
\hline Total & 400 & 100.0 \\
\hline
\end{tabular}

\section{Age}

$86.7 \%$ of patients with overt diabetes were in the age group of more than 25 years compared to $13.3 \%$ in the age group $<25$ years. The observed difference is statistically significant. Patients in the age group of more than 25 years have 4.9 times more risk of overt diabetes than women in the age group of less than 25 years.

\section{History of abortion}

$46.7 \%$ of patients with overt diabetes had history of abortion whereas only $17.9 \%$ of patients without diabetes. The observed difference is statistically significant. Patients with overt diabetes have 4 times more risk of abortion than those without overt diabetes. No difference shown between high and low income groups and urban and rural areas.6.7\% of overt diabetes belong to higher socio economic group compared to $5.7 \%$ in the non-diabetic group.

\section{Family history}

$73 \%$ of overt diabetes have family history of diabetes whereas only $46 \%$ in non-diabetic. Hence this is statistically significant. No association with exercise was demonstrated in the study.

Table 2: Association of history of IUD in previous pregnancy.

\begin{tabular}{|l|l|l|l|l|l|l|}
\hline \multirow{2}{*}{ IUD } & \multicolumn{3}{l}{ Overt DM } & \multicolumn{3}{l|}{ Total } \\
& Present & \multicolumn{2}{l|}{ Absent } & \multicolumn{2}{l|}{ Total } \\
\hline Present & 6 & 40 & $\mathrm{~N}$ & $\%$ & $\mathrm{~N}$ & $\%$ \\
\hline Absent & 9 & 60 & 358 & 93 & 367 & 92 \\
\hline Total & 15 & 100 & 385 & 100 & 400 & 100 \\
\hline
\end{tabular}

$\mathrm{P}<0.001 \mathrm{OT}=8.84095, \mathrm{CI}$ for $\mathrm{OR}=2.929-26.677$

People with overt diabetes have 8.8 time more chance of having IUD in previous pregnancy than non-diabetes. 
Table 3: Frequency of history of gestational diabetes in previous pregnancy.

\begin{tabular}{|c|c|c|c|c|c|c|}
\hline \multirow{3}{*}{$\begin{array}{l}\text { GDM in } \\
\text { previous } \\
\text { pregnancy }\end{array}$} & \multicolumn{6}{|c|}{ Overt DM } \\
\hline & \multicolumn{2}{|c|}{ Present } & \multicolumn{2}{|c|}{ Absent } & \multicolumn{2}{|c|}{ Total } \\
\hline & $\mathrm{N}$ & $\%$ & $\mathrm{~N}$ & $\%$ & $\mathrm{~N}$ & $\%$ \\
\hline Present & 9 & 60 & 93 & 24 & 102 & 26 \\
\hline Absent & 6 & 40 & 292 & 76 & 298 & 75 \\
\hline Total & 15 & 100 & 385 & 100 & 400 & 100 \\
\hline
\end{tabular}

$60 \%$ of pregestational diabetes had history of gestational diabetes in previous pregnancy.

Table 4: Frequency of hypo-thyroidism.

\begin{tabular}{|c|c|c|c|c|c|c|}
\hline & \multicolumn{6}{|c|}{ Overt diabetes } \\
\hline & \multicolumn{2}{|c|}{ Present } & \multicolumn{2}{|c|}{ Absent } & \multicolumn{2}{|c|}{ Total } \\
\hline $\begin{array}{l}\text { Thyroid } \\
\text { disorder }\end{array}$ & $\mathrm{N}$ & $\%$ & $\mathrm{~N}$ & $\%$ & $\mathrm{~N}$ & $\%$ \\
\hline Present & 12 & 80 & 173 & 45 & 185 & 46 \\
\hline Absent & 3 & 20 & 212 & 55 & 215 & 54 \\
\hline total & 15 & 100 & 385 & 100 & 400 & 100 \\
\hline
\end{tabular}

Association of hypothyroidism in women with pre gestational diabetes was found to be statistically significant.

Table 5: Association of candidiasis and overt diabetes.

\begin{tabular}{|l|l|l|l|l|l|l|}
\multirow{2}{*}{ Candidiasis } & \multicolumn{3}{l}{ Prert DM } & \multicolumn{2}{l|}{ Absent } & \multicolumn{2}{l|}{ Total } \\
\cline { 2 - 8 } & N & $\%$ & N & $\%$ & N & $\%$ \\
\hline Present & 3 & 20 & 5 & 1.3 & 8 & 2 \\
\hline Absent & 12 & 80 & 380 & 99 & 392 & 98 \\
\hline Total & 15 & 100 & 385 & 100 & 400 & 100 \\
\hline
\end{tabular}

$\mathrm{P}<0.001$ OR 19.00

Overt diabetic patients have 19 times more chance of candidiasis than nondiabetics.

\section{History of IUD}

$40 \%$ of overt diabetes had history of IUD compared to $7 \%$ in non-diabetic. The observed difference is statistically significant. Women with overt diabetes had 8.8 times more chance of having IUD.

\section{History of GDM}

$60 \%$ of overt diabetes had history of GDM in previous pregnancy compared to $24 \%$ in non-diabetic group. The observed difference is statistically significant.

\section{History of UTI}

$60 \%$ overt diabetes and $41 \%$ of non-diabetics had UTI which is not statistically significant.

\section{Candidiasis}

$20 \%$ of overt diabetes had candidiasis whereas only $1.3 \%$ in non-diabetic. The observed difference is statistically significant. Overt diabetics had 19 times more chance of candidiasis.

\section{Thyroid disease}

$80 \%$ of overt diabetes had history of thyroid disease compared to $45 \%$ in non-diabetic. The observed difference is statistically significant. Overt diabetics have 4 times more chance of thyroid disease.

\section{DISCUSSION}

Pre gestational diabetes has lot of implications for both mother and foetus. $\mathrm{HbA1C}$ in the first trimester was checked in 400 ante natal women attended in the OPD irrespective of their diabetic status with $6.5 \%$ taken as cutoff for diagnosis of diabetes.

WHO in 2011 as well as ADA has accepted HbA1C as a diagnostic tool for Diabetes mellitus. ${ }^{1-3}$

First national study of prevalence of diabetes in India was done by ICMR between 1972 - 1975 reported a prevalence of $2.1 \%$ in urban population and $1.5 \%$ in rural population. Subsequent studies showed a rising shift in younger age of onset of diabetes prevalence of diabetes in India $4.7 \%$ in urban compared to $2 \%$ in rural population. $^{4,5}$ The increase in preexisting diabetes particularly in young women early in their reproductive years is of concern. ${ }^{6}$

Prevalence of pre-gestational diabetes in our study population was $3.8 \%$. This is more than the observed prevalence in other studies which is around $1.3 \% .^{6}$ This difference may be because our population is from a tertiary care center and most of the cases were referred cases. Among 400 patients $3.8 \%$ patients had pregestational diabetes. Among these $86.7 \%$ were having Type 2 diabetes and $13.3 \%$ had Type 1 diabetes.

\section{Associations}

Age- $86.7 \%$ of patients with pre-gestational diabetes were in the age group of more than 25 years compared to $56.6 \%$ of women in nondiabetic group. Women in the age group of more than 25 years have 4.9 times more risk of overt diabetes than in the age group of $<25$ years. This is comparable to other studies. ${ }^{6,7}$

Socio economic status- $6.7 \%$ overt diabetes belonged to higher socioeconomic status compared to $5.7 \%$ of nondiabetics. The difference is not statistically significant. This may be due to the fact that majority of (93\%) the study group belonged to low socioeconomic status. High prevalence of diabetes in low socio economic group reported in other studies. ${ }^{6,7}$ 
BMI-46.2\% of pre-gestational diabetes had BMI >25 $\mathrm{kg} / \mathrm{m}^{2}$ compared to $19.2 \%$ in non-diabetics. This is statistically significant. Women with BMI of $>25 \mathrm{~kg} / \mathrm{m}^{2}$ had 3.6 times more chance of overt diabetes than those with $\mathrm{BMI}<25 \mathrm{~kg} / \mathrm{m}^{2}$. This is comparable to other studies where it was shown that pregnant women with pregestational diabetes were older and had higher BMI. ${ }^{8,9}$

\section{History of abortion}

$46.7 \%$ of women with pre-gestational diabetes had history of abortion compared to $17.9 \%$ of nondiabetics. This association is significant as women in overt diabetes have four times more chance of abortion than those without diabetes.

Glycosylated hemoglobin levels were significantly higher in those women who aborted spontaneously than in women who delivered successfully. These results emphasize the adequacy of diabetic control in the first trimester and lend further support to the importance of good control at this critical time in insulin-dependent diabetes. ${ }^{10}$

\section{History of IUD}

There is significant association between history of IUD and pre-gestational diabetes in our study. Women with pre-gestational diabetes were 8.8 times more likely to have IUD. This is comparable to other studies. ${ }^{11}$ Pregestational diabetes increases the risk of fetal death by around 4.5 times compared to those without diabetes and doubles the risk of infant deaths. ${ }^{12,13}$

\section{History of gestational diabetes}

In previous pregnancy- There is significant association between history of gestational diabetes and overt diabetes $(p=0.0002)$ in our study. This is comparable to other studies. Women with history of gestational diabetes represent a high-risk group with an increased risk of overt diabetes and obstetric complications. ${ }^{14}$

Family history of diabetes- $73 \%$ of pre-gestational diabetes had given family history of diabetes which is found to be statistically significant in our study. This correlation was demonstrated in previous studies as genes play an important role in development of diabetes. ${ }^{15}$ Hyperglycemic intrauterine environment plays an important role in pathogenesis of type 2 diabetes. ${ }^{16}$

\section{Hypothyroidism}

$80 \%$ of overt diabetics had history of thyroid disease compared to $45 \%$ in the non-diabetic group in our study which is statistically significant $(\mathrm{P}=0.008)$. Thyroid dysfunction tend to co-exist as both conditions involve a dysfunction of endocrine system. This is documented in other studies. ${ }^{16,17}$

\section{Candidiasis}

$20 \%$ of pre-gestational diabetes had candidiasis compared to $1.3 \%$ in non-diabetic. It is statistically significant (p $<0.001$ ). Overt diabetes patients had 19 times of more chance of candidiasis. This is comparable to other studies. ${ }^{18,19}$

\section{CONCLUSION}

Prevalence of pre-gestational diabetes was $3.8 \%$ in our study group. Age $>25$ years, BMI, family history of diabetes, history of GDM in previous pregnancy, history of IUD, History of abortion, Thyroid disorder and candidiasis were found to have significant association with diabetes.

Early screening of diabetes should be started in the first trimester of pregnancy so that pre-gestational diabetes can be diagnosed and proper counselling and management is possible so as to prevent complications.

Funding: No funding sources

Conflict of interest: None declared

Ethical approval: The study was approved by the Institutional Ethics Committee

\section{REFERENCES}

1. Chen L, Magliano DJ, Zimmet PZ. The worldwide epidemiology of type 2 diabetes mellitus present and future perspectives. Nature Reviews Endocrinology. 2012;8:228-36.

2. Tankova T, Chakarova N, Iliana DA. Assessment of HbA1c as a diagnostic tool in diabetes and prediabetes. Acta Diabetologica. 2012;49(5):371-8.

3. Rajput R, Yadav Y, Rajput M, Nanda S. Utility of HbA1c for diagnosis of gestational diabetes mellitus. Diabetes Research Clinical Practice. 2012;98(1):1047.

4. Anjana RM, Pradeepa R, Deepa M, Datta M, Sudha V, Unnikrishnan RA, et al. Prevalence of diabetes and prediabetes (impaired fasting glucose and/or impaired glucose tolerance) in urban and rural India: phase I results of the Indian council of medical research India. Diabetes. 2011;54(12):3022-7.

5. Mohan V, Sandeep S, Deepa R, Shah B, Varghese C. Epidemiology of type 2 diabetes: Indian scenario. Indian J Med Res. 2007;125(3):217-30.

6. Doreen MR, Edwards AL, Danielle A, Lawrence WS, Peter MS, Norton P, et al. Association of socioeconomic status with diabetes prevalence and utilization of diabetes care services. BMC Health Services Research. 2006;6:124.

7. Evans JM, Newton RW, Ruta DA, Macdonald TM, Morris AD. Socio-economic status, obesity and prevalence of Type 1 and Type 2 diabetes mellitus Diabet Med. 2000;17(6):478-80.

8. Lindsay RS, Hanson RL, Bennett PH, Knowler WC. Secular trends in birth weight, BMI and diabetes in 
the offspring of diabetic mothers. Diabetes Care. 2000;23(9):1249-54.

9. William $\mathrm{CH}$, Rosario MG, Alka AM. BMI cut points to identify at-risk asian americans for type 2 diabetes screening. Diabetes Care. 2015;38(1):150-8.

10. Wright AD, Nicholson HO, Pollock A, Taylor TG. Betts spontaneous abortion and diabetes mellitus. Postgrad Med J. 1983;59(691):295-8.

11. Korteweg FJ, Jaap HM, Erwich. Evaluation of 1025 fetal deaths: proposed diagnostic workup. Am J Obst Gynec. 2012;206(1):1-12.

12. Tennant PW, Glinianaia SV, Bilous RW. Bell, preexisting diabetes, maternal glycated haemoglobin and the risks of fetal and infant death: a populationbased study. Diabetologia. 2014;57(2):285-94.

13. Clausen TD, Mathiesen ER, Hansen T. High prevalence of type 2 diabetes and pre-diabetes in adult offspring of women with gestational diabetes mellitus or type 1 diabetes the role of intrauterine hyperglycemia. Diabetes Care. 2008;31(2):15-8.

14. Haroush BA, Yogev Y, Hod M. Epidemiology of gestational diabetes mellitus and its association with type 2 diabetes. Diabet Med. 2004;21(2):103-13.
15. Radha V, Mohan V. Genetic predisposition to type 2 diabetes among Asian. Indian J Med Res. 2007;125:259-74.

16. Hage M, Zantout MS, Azar ST. Thyroid disorders and diabetes mellitus. J Thyroid Res. 2011;439463:7.

17. Kadiyala R, Peter R, Okosieme OE. Thyroid dysfunction in patients with diabetes: clinical implications and screening strategies. Int $\mathrm{J}$ Clin Pract. 2010;64(8):1130-9.

18. Malazy OT, Shariat M, Heshmat R, Majlesi F, Alimohammadian M, Tabari NK, et al. Vulvovaginal candidiasis and its related factors in diabetic women. Taiwan J Obstet Gynecol. 2007;46(4):399-404.

19. Goswami R, Dadhwal V, Tejaswi S, Datta K, Paul A, Haricharan RN, et al. Species-specific prevalence of vaginal candidiasis among patients with diabetes mellitus and its relation to their glycaemic status. J Infect. 2000;41(2):162-6.

Cite this article as: Renji SR, Lekshmi ST, Chellamma N. Prevalence of pre-gestational diabetes among the antenatal women attending a tertiary care center. Int J Reprod Contracept Obstet Gynecol 2017;6:797-801. 